\title{
The smallpox eradication game
}

\author{
Scott Barrett
}

Received: 16 December 2005 / Accepted: 31 May 2006

(C) Springer Science + Business Media B.V. 2006

\begin{abstract}
Why did the world succeed in eradicating smallpox? Though eradication is a global public good, theory suggests that it should not have been vulnerable to free riding. Some countries, however, lacked the capacity to eliminate smallpox. Success thus depended on the other countries providing assistance. Theory suggests that this public good also should not have been vulnerable to free riding. However, financing proved challenging, even though the global benefit-cost ratio for eradication exceeded 400:1. Contrary to what theory suggests, what may have been the greatest achievement of international cooperation ever was not inevitable. Indeed, it very nearly failed.
\end{abstract}

Keywords Smallpox · Disease eradication · Global public good · International financing · International cooperation

\section{Introduction}

The global eradication of smallpox, certified in 1979, is a unique achievement in the history of international cooperation. Every previous attempt to eradicate disease failed. Even when compared with international cooperation in other areas, smallpox stands out as an exception. With a benefit-cost ratio of over 400:1, the international effort to eradicate smallpox was probably the best collective investment the world ever made. ${ }^{1}$

\footnotetext{
S. Barrett

School of Advanced International Studies, Johns Hopkins University, 1619 Massachusetts Avenue NW, Washington, DC 20036-1984, USA; Yale Center for the Study of Globalization, Yale University e-mail: sbarrett@jhu.edu

${ }^{1}$ The other great achievement of international cooperation was protection of the stratospheric ozone layer an effort begun in 1987 and that is now expected to restore the ozone layer to near its original concentration level by 2050 . The benefit-cost ratio for ozone layer protection was also exceptional (see Barrett, 2003a). While it is difficult to make a direct comparison with smallpox, the costs of both efforts were modest relative to the benefits, and the benefits of smallpox eradication were almost certainly greater. Smallpox killed about 1.5 million people a year when the intensified program began in 1967, whereas the ozone treaty is expected to avoid about one-third of a million deaths in total through 2060. See Barrett (2003a, Table 8.2).
} 
Smallpox could only be eradicated globally if the disease were eliminated in every country. If just one country harbored the disease, all others would remain vulnerable. For example, over the period 1961-75, Europe imported smallpox from India on ten separate occasions (Basu et al., 1979: 84). In none of these cases was an epidemic triggered - but this is only because Europe maintained high immunization rates, precisely to guard against such a threat. Eradication thus not only saved millions of lives in the countries in which the disease remained endemic at the start of the intensified campaign (that is, in countries like India; see Fenner et al., 1988: 1346). It also removed the need to defend against imports, by administering a costly - and, sometimes, risky - live vaccine elsewhere (especially Europe and North America). ${ }^{2}$ Cooperation by every country was needed to achieve eradication, but the achievement in turn benefited every country.

Eradication is a high stakes game, and could fail for any number of reasons. The ongoing effort to eradicate the regional disease, Guinea worm, for example, has been stopped in its tracks by the decades-long civil war in Sudan (Hopkins et al., 2002). The smallpox campaign was luckier. A ten-year cease-fire just happened to be in effect in Sudan during a key stage of the eradication effort: otherwise, eradication may not have been possible. But while many of the things that could have gone wrong did not, the smallpox eradication effort nevertheless came close to failing because of a lack of funding. As the team that led the effort later explained, the

\begin{abstract}
"lack of resources constituted a serious, continuing problem and, even in the concluding years of the programme, those that were made available barely sufficed to sustain momentum. Donated vaccine, for example, was continually in short supply despite repeated appeals for assistance. The World Health Assembly was informed on a number of occasions of the need for additional funds, amounting to no more than a few million US dollars, and such funds were sought in correspondence and in meetings with potential donors, but the response was never adequate.... Success was never a certainty even during the years immediately preceding the last known cases." 3
\end{abstract}

Problems of this kind are perhaps to be expected since eradication is a pure global public good and the international organization in charge of the campaign, the World Health Organization (WHO), "had no authority, other than that of moral suasion, to compel any country to initiate a programme, adhere to a plan or strategy, or contribute towards its support" (Fenner et al., 1988: 422). Even the effort to control bovine tuberculosis in the United States required federal funding and the coercive powers of state intervention. ${ }^{4}$ However, the economics of eradication are very different from control, and this makes the incentives for provision different, too. ${ }^{5}$

\footnotetext{
${ }^{2}$ In 1968, there were 566 complications per million vaccinations in the US. Nine people died from smallpox vaccination that same year. See Sencer and Axnick (1973).

${ }^{3}$ Fenner et al. (1988: 423).

${ }^{4}$ See Olmstead and Rhode (2004). Bovine tuberculosis was not truly "eradicated." It was controlled to a very high level within the US. Smallpox is the only disease to have been eradicated. For a discussion of the relevant definitions, see Miller, Barrett, and Henderson (2006).

${ }^{5}$ See Barrett and Hoel (2003) and Barrett (2004).

Springer
} 
Eradication is a weakest link public good; it only succeeds if the country with the weakest control program eliminates the disease. ${ }^{6}$ In a model with symmetric countries, there are four possible situations (Barrett, 2003b): it may not pay any country to eliminate the disease, irrespective of what others do - an outcome that is either (1) efficient or (2) inefficient (that is, a prisoners' dilemma), depending on the costs and benefits; (3) it may pay every country to eliminate the disease, irrespective of whether other countries do so (an outcome that is obviously efficient); and (4) it may pay every country to eliminate the disease only if all others have eliminated it (a coordination game with two Nash equilibria only one of which is efficient).

This theory provides a useful benchmark, but the real smallpox game was characterized by substantial asymmetries. By the time the eradication program began, the rich countries had already eliminated smallpox within their borders. Eradication would succeed only if the remaining endemic countries eliminated the disease. Very roughly, the smallpox eradication game seems to have reflected some combination of cases (3)-(4). By examining the costs and benefits of eradication to various countries, I shall show that the rich countries had an incentive to eliminate smallpox unilaterally, but that the situation for the poor countries was more complicated. Many poor countries had an incentive to eliminate unilaterally, but lacked the capability to do so - just as they lacked the capability to supply many national public goods. Some developing countries may have had an incentive to eliminate the disease only if assured that eradication would succeed, but these countries are also likely to have been unable to eliminate the disease within their borders without international assistance.

Since many countries would gain from eradication, this asymmetry transformed the game from one of countries choosing their control policies to one of some countries offering technical and financial assistance to others. Financing under such circumstances can increase cooperation (Barrett, 2001), but here the incentive to offer finance is particularly strong because eradication is a threshold public good. Indeed, if full provision is efficient (as it was in the case of smallpox eradication), there can only two possible situations. Either financing is a coordination game, in which case full financing is $a$ Nash equilibrium, or at least one country gains enough from eradication to make full financing the unique Nash equilibrium. Either way, an agreement to eradicate smallpox should not have needed to be enforced. Smallpox eradication was not a prisoners' dilemma.

As I shall explain, the evidence overwhelmingly suggests that full financing of smallpox eradication was the unique Nash equilibrium. In Olson's (1965) terminology, the world was "privileged." Analytical game theory thus suggests that full financing should have proved easy, and yet we know that it was not. A hint as to why this might be so is also to be found in Olson's famous book. In a footnote, Olson (1965: 50) warns that "a 'privileged' group might not provide itself with a collective good, since there might be bargaining within the group and this bargaining might be unsuccessful." That is, while many countries would have had a strong incentive to finance the eradication effort, each would have preferred that others paid instead. As we shall see, bargaining difficulties do help explain why financing of the smallpox eradication program proved difficult.

A different explanation relates to Olson's hypothesis about domestic politics and lobbying by large groups. The above analysis assumes that states are monoliths, but of course they are not; they represent the interests of a variety of domestic groups. The benefits of eradication

\footnotetext{
6"Elimination" here means controlling to a level sufficient to ensure that the disease is no longer endemic. Imports can cause infection, but cannot spark an epidemic. For a classification of public goods, including summation and weakest link public goods, see Hirshleifer (1983) and Sandler (1992).
} 
were highly diffused, and no powerful domestic group advocated for its provision. Putnam (1988) argues that, under such conditions, international negotiations will fail provided that a domestic group lobbies against its provision. Smallpox eradication would not have harmed any group, and no group lobbied against it. ${ }^{7}$ Hence, it seems that, at least in this case, the absence of harm was not sufficient for success. Provision of this global public good may rather have depended on a domestic group lobbying in favor of the policy.

Understanding all of this is of more than historical interest, for the world is now attempting to eradicate another global scourge, poliomyelitis, and while the outcome of this campaign will depend on more than finance, a WHO report on the polio eradication effort asserted that a lack of finance constituted "the single greatest threat to realizing the historic eradication goal" (WHO, 2001: 1). ${ }^{8}$ As well, there are other candidates for eradication. These include, at a minimum, hepatitis B, rubella, and measles (Hinman, 1999). Moreover, international finance is essential to the supply of many other global public goods, including the securing of "loose nukes," surveillance of emerging infectious diseases like pandemic influenza, and global climate change mitigation. These challenges differ from eradication in a number of respects, but our chances of supplying these global public goods will surely be helped by understanding how the greatest success so far was achieved, and why, at the same time, this effort nearly failed. ${ }^{9}$

\section{Brief history}

Smallpox became adapted to humans as an endemic disease in Egypt or India sometime before 1000 BC (Hopkins, 1983: 20). With increased trade and movements of people, the disease spread around the world, helping to advance European imperialism, and becoming endemic in areas with large populations (Crosby, 1986; McNeill, 1976). Smallpox was controlled by a number of means, including inoculation (variolation) and quarantine. Inoculation was practiced in Europe and North America from the early 18th century, but it was used for centuries before that in China, India, and probably parts of Africa. Inoculation was risky: it had a fatality rate of up to three percent and also facilitated spread of the disease. Vaccination, the efficacy of which was demonstrated in Edward Jenner's famous 1798 pamphlet, was superior in every way - so much so that its use "spread with remarkable speed, in sharp contrast with to the slow adoption of variolation in most European countries" (Fenner et al., 1988: 231).

Some people resisted vaccination, however, and epidemics kept recurring, though on a much smaller scale than before. There were a number of reasons for this: variolation, still in use, helped to spread the disease; vaccination was sometimes incompetently administered; revaccination was needed to provide lasting immunity; and the vaccine itself posed a risk, killing about one in 14,000 people vaccinated (Glynn \& Glynn, 2004: 153). To prevent further epidemics, legislation was introduced making vaccination compulsory. In Britain, for

\footnotetext{
${ }^{7}$ It might seem that the vaccine manufacturers would oppose eradication, since a successful effort would destroy their market. The market for vaccines, however, was highly competitive. In 1967, there were 77 manufacturers of freeze-dried smallpox vaccine in 52 countries (Fenner et al., 1988: 543).

${ }^{8}$ As of April 2005, there is a $\$ 50$ million funding gap for 2005, and an additional \$200 million gap for 2006; see WHO (2005).

${ }^{9}$ In an important paper, Cooper (1989) also examines the reasons for the success of international cooperation in eradicating smallpox. His main concern, however, is with the importance of establishing the technical feasibility of eradication. My interest lies in the financing of the global program.
} 
example, an 1840 Act banned variolation and provided vaccination free of charge - the first free medical service offered in the country. Administration of the law, however, provoked resistance - among the poor, because vaccination was made the responsibility of the Poor Law Commissioners; and among doctors, who complained that they were paid too little for their services. The authorities responded to the weak compliance by tightening the grip of their not-so-invisible hand: an 1853 act made vaccination compulsory, with violations subject to fines; and follow-up laws increased these fines, adding repeated penalties for non-compliance. Every tightening in the laws, however, only increased social resistance. Eventually a new approach was tried. The 1898 Vaccination Act gave parents the right to refuse to vaccinate their children. This law proved more popular: a quarter of a million certificates were awarded to "conscientious objectors" in the first year (Glynn \& Glynn, 2004: 163).

This tension between the individual and the public interest is ubiquitous and persists to the present day. For example, fewer than one in ten civilians targeted by the Bush Administration's plan to prepare for a possible bioterrorist attack consented to be vaccinated for smallpox. Resistance to vaccination is to be expected, especially for this most risky of vaccines. Vaccination of an individual offers more than private protection; it also offers a measure of protection to the public at large. Individuals, however, have no incentive to take account of this externality. So there is a rationale for intervention by the state - and, yet, compulsion only exposes the tension that exists between private and public interests. ${ }^{10}$ The possibility of intervention by the state, however, introduces yet another incentive problem. If countries make their vaccination choices independently, the Nash equilibrium as regards state behavior may fail to eradicate the disease, even though every country may be better off if the disease were eradicated. This is the incentive problem noted in the introduction. It is the focus of the rest of this paper.

Jenner understood immediately that vaccination made eradication feasible. Writing in 1801 , he noted that "it now becomes too manifest to admit of controversy, that the annihilation of the Small Pox, the most dreadful scourge of the human species, must be the final result of this practice." Thomas Jefferson, writing to Jenner in 1806, agreed, predicting that future generations would "know by history only that the loathsome smallpox has existed" (Hopkins, 1983: 310). The possibility of eradicating smallpox did not attract global attention, however, until 1953 when the WHO's first Director General, Brock Chisholm, proposed to the World Health Assembly (WHA), the legislative arm of the WHO, that smallpox be eradicated. Perhaps surprisingly in hindsight, the proposal failed to win broad support. Countries as diverse as India and El Salvador, the UK and Pakistan, and the US and Venezuela argued that "the problem of smallpox was really a regional or even a local one" (Fenner et al., 1988: 392).

In 1959, a resolution recommending that smallpox be eradicated was submitted by the USSR to the WHA, and received unanimous backing. By this time, smallpox had already been eliminated from many industrialized countries, but remained endemic in about 59 poor countries (Fenner et al., 1988: 393-394). Achievement of the eradication goal thus depended on eliminating the disease in these countries (and, of course, preventing smallpox from being imported and re-established elsewhere).

Though all countries supported the eradication goal, the resolution failed to provide the resources needed to achieve its ambition. The WHO estimated that $\$ 97.7$ million was needed to eliminate smallpox in the remaining endemic countries, but the organization allocated less than 0.2 percent of this amount to smallpox from its 1960 budget - just a tiny bit more than

\footnotetext{
${ }^{10}$ Barrett (2003b) shows that the Nash equilibrium in individual vaccination choices is inefficient; aggregate welfare is increased if vaccination levels are increased above the "competitive" level.
} 
it had given before the resolution passed. ${ }^{11}$ After this, the program continued to be starved of resources. Special funds were not made available, and the WHO declined to divert any more of its budget to smallpox. Despite repeated requests for voluntary contributions, few countries gave to the campaign. From 1959 to 1966, only eight countries donated cash: a grand total of just $\$ 27345$. Contributions in kind (usually vaccine) were more generous, but still insufficient. For example, though 15 million doses were pledged following an emergency appeal in 1963, less than half of the doses supplied met the WHO's minimum quality standards - a small fraction of the amount needed to eliminate smallpox in just one country (India) in just one year.

In 1965, President Lyndon Johnson gave the effort a belated jump start by pledging "American support for an international program to eradicate smallpox completely from the earth within the next decade" (Fenner et al., 1988: 407), and offering bilateral aid with the aim of eliminating smallpox in 20 contiguous western and central African countries.

With momentum possibly building, the WHO revised its estimate of the funds needed to eradicate smallpox. The new estimate of $\$ 180$ million was almost twice the earlier figure, with $\$ 48.5$ million needing to be contributed by international sources. The plan, published in $1966-$ a time when smallpox remained endemic in 31 countries - called for eradication to be achieved within a decade. ${ }^{12}$ Subtracting the assistance pledged by the US, the international effort needed to eliminate smallpox in about twenty endemic countries: a more manageable task. ${ }^{13}$

It is worth underlining that, under the WHO's plan, endemic countries would pay about 70 percent of the total required expenditure. International assistance was to finance only the remaining 30 percent. ${ }^{14}$ Essentially, the endemic countries agreed to pay for the costs of their own vaccination staff, with the international community supplying the vaccine and technical expertise. ${ }^{15}$

International financing was to come from three main sources: mandated contributions, agreed by a vote of the WHA, bilateral contributions (including the aid given by the US to Africa), and voluntary contributions paid into a special account. Small amounts were also contributed by UN agencies other than the WHO.

The mandated contributions are especially interesting. Every year, the WHA approves an overall budget for the WHO, and in 1966 the WHO asked members to approve an additional, separate budget for an intensified smallpox eradication program. Why a separate budget? If countries were serious about eradication, the WHO reasoned, then they should be willing to pay for it.

The Director-General proposed a budget of just $\$ 2.415$ million for 1967 - just over a third of the total level of international assistance needed that year. Given the scale of assessments for 1966, this implied a contribution of less than \$1 million for the US - as we shall see later, a tiny fraction of the annual cost to the US of vaccinating its own population.

\footnotetext{
${ }^{11}$ Fenner et al. (1988), Table 9.1, p. 369.

${ }^{12}$ Countries with endemic smallpox in 1967 include: in Africa, Burundi, Cameroon, Dahomey (Benin), Democratic Republic of the Congo, Ethiopia, Ghana, Guinea, Kenya, Liberia, Malawi, Mali, Mozambique, Niger, Nigeria, Rwanda, Sierra Leone, South Africa, Southern Rhodesia (Zimbabwe), Togo, Uganda, United Republic of Tanzania, Upper Volta (Burkina Faso), and Zambia; in the Americas, Brazil; and in Asia, Afghanistan, East Pakistan (Bangladesh), India, Indonesia, Nepal, West Pakistan (Pakistan), and Yemen. See Fenner et al. (1988: 518).

${ }^{13}$ Some of the African countries receiving support from the US did not have endemic smallpox in 1967.

${ }^{14}$ International funds essentially covered the difference between the amounts spent by the endemic countries to control smallpox before the intensified program began and the amounts needed to eliminate the disease. This can be seen clearly in Ramaiah's (1976) analysis for India. See especially Table III on p. 176. According to Ramaiah's estimates, international assistance increased funding by about 36 percent.

${ }^{15}$ Personal communication, D. A. Henderson, 24 September 2003. 
Table 1 World Health Assembly vote on the smallpox eradication budget

\begin{tabular}{lllllll}
\hline & $\begin{array}{l}\text { Number of } \\
\text { members present } \\
\text { and voting }\end{array}$ & $\begin{array}{l}\text { Two-thirds } \\
\text { majority }\end{array}$ & In favor & Against & Abstentions & Outcome \\
\hline France & 84 & 56 & 18 & 66 & 17 & Rejected \\
United States & 90 & 60 & 36 & 54 & 7 & Rejected \\
Director-General & 86 & 58 & 60 & 26 & 12 & Approved \\
\hline
\end{tabular}

Source: Eighth meeting of the nineteenth World Health Assembly, 12 May 1966, Official Records of the World Health Organization, 152: 288

Though small relative to the need and the benefit, the combined WHO budget requested in 1966 represented a 22 percent increase over the previous year (Fenner et al., 1988: 409), and a number of countries opposed the increase. France proposed a smaller budget for smallpox - just \$1 million - and the US (with the support of the United Kingdom and Iraq) countered by proposing a compromise budget of $\$ 1.4$ million. The WHA rejected both alternatives in favor of the Director-General's proposal, but approved the latter by a margin of just two votes - "the narrowest margin for the acceptance of a budget in the Organization's history" (Fenner et al., 1988: 416). The results of the voting are shown in Table 1.

Official records conceal how individual countries voted, but Fenner et al. (1988: 416) provide additional information. The French proposal, they say, was supported by Canada, Italy, Turkey, and the USSR; the US proposal by Australia, Austria, Belgium, the Federal Republic of Germany, Iraq, Japan, the Netherlands, Pakistan, and the United Kingdom; and the Director-General's proposal by Finland, Norway, Sweden, Switzerland, and 19 developing countries. ${ }^{16}$ This means that the ten biggest contributors to the WHO budget, accounting for three-quarters of all assessments over the course of the intensified campaign (1967-1979), supported weaker funding. Of the countries with lower assessments, support for the Director-General's proposal was divided. Endemic countries would receive direct assistance, but developing countries already smallpox-free would not benefit directly from the extra expenditure. Like the industrialized countries, they would only benefit if the entire effort actually succeeded.

The success of the eradication effort thus still depended on voluntary contributions, and previous experience warned against optimism. Indeed, two senior members of the WHO's Smallpox Eradication Unit, D. A. Henderson and Isao Arita, wrote to their divisional director to protest against the plan. "In the light of recent past experience," they wrote, "we question whether this [reliance on voluntary funding] is sound. .." (Fenner et al., 1988: 414).

Why ask for so little? One reason is that the Director-General did not believe smallpox eradication could succeed, irrespective of the amounts contributed (Fenner et al., 1988: 417). ${ }^{17}$ A second reason is that a larger request would likely have been voted down. As noted above, support for the Director-General's budget was weak, and no country proposed a larger budget. This last explanation is perplexing, because it suggests that the mandated

\footnotetext{
${ }^{16}$ Pakistan, an endemic country, seems to be an outlier among supporters of the US proposal. Pakistan's representative explained after the vote, almost apologetically, that he had supported the US proposal "because, while wishing to demonstrate his country's interest in the smallpox eradication programme, he had been obliged to bear in mind its capacity to pay assessments" (World Health Assembly, 1966: 288).

${ }^{17}$ According to Fenner et al. (1988: 417), the Director-General was against "imposing on countries a special programme like that for malaria eradication. As he saw the situation, the prospects for success depended on progress in the development of each country's basic health services."
} 


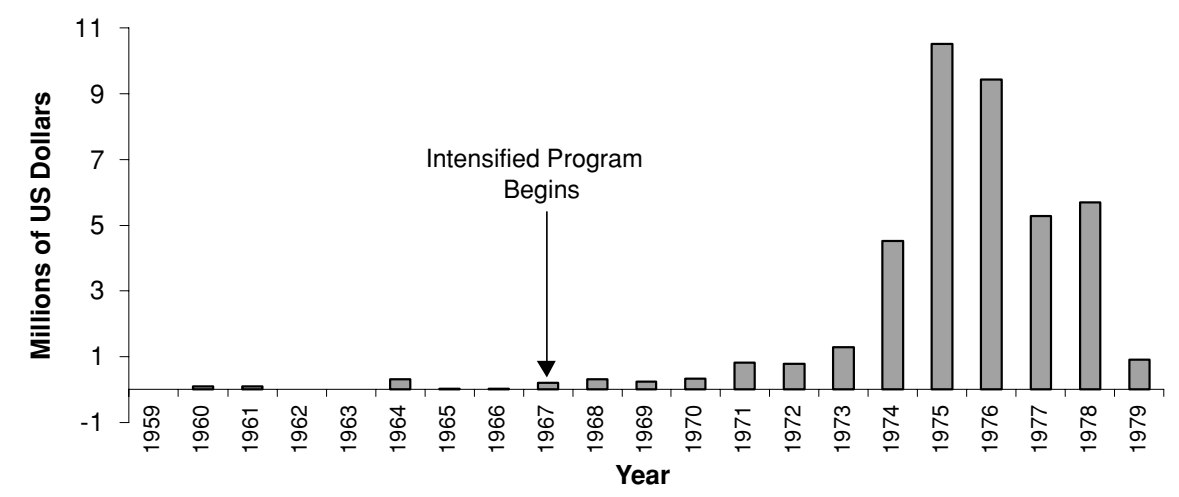

Source: Fenner et al., 1988, Table 10.7, p. 466.

Fig. 1 Contributions in cash and in kind to WHO voluntary fund special account for smallpox eradication

contributions would be wasted. Why would countries vote to finance a program that had no chance of succeeding unless more money was contributed? Later in this paper I shall suggest a third possible reason that answers this question: a larger mandatory contribution may not have been necessary; the mandatory contribution may have served as the "seed money" needed to increase the incentive for countries to contribute voluntarily to the program. ${ }^{18}$

What actually happened? As shown in Figure 1, voluntary funds only trickled in between the time the eradication goal was endorsed in 1959 and the intensified eradication program was approved in 1966. Even after this, voluntary contributions were inadequate; from 1967 to 1973 , cash donations totaled only $\$ 79,500$ (Henderson, 1999). At this point, the fears expressed by Henderson and Arita appeared to be confirmed. Starting in 1974, however, voluntary funding increased substantially; and it remained substantial up to the time eradication was finally certified. Indeed, as Figure 2 shows, the final stages of the eradication campaign were funded almost entirely by voluntary contributions. By the time victory was declared, $\$ 97.97$ million in international assistance had been collected.

\section{Phases}

The history of the smallpox eradication game suggests that perceptions about the nature of the challenge evolved. Three distinct phases stand out.

Before 1959, smallpox eradication was perceived to be a problem for national governments to solve. Recall that smallpox had already been eliminated in many countries by $1959 .{ }^{19}$ In Europe, Japan, and North America, elimination was achieved unilaterally. In Central and South America, elimination was helped by the Pan American Sanitary Organization (today, the Pan American Health Organization or PAHO), which pledged limited resources to a goal of regional elimination (\$75,000 in 1952 and $\$ 144,000$ in 1954; see Fenner et al., 1988: 389). However, even under PAHO, the "responsibility for the execution of national programmes and for their cost was left essentially to the respective governments" (Fenner et al., 1988:

\footnotetext{
${ }^{18}$ Interview with D. A. Henderson, 25 November 2003. As the gap in financing decreases, the returns per dollar on the investment needed to close the gap increase.

${ }^{19}$ In Europe, the first three countries to eliminate smallpox were Iceland (1872), Sweden (1898), and Norway (1898); see Fenner et al. (1988: 322). 


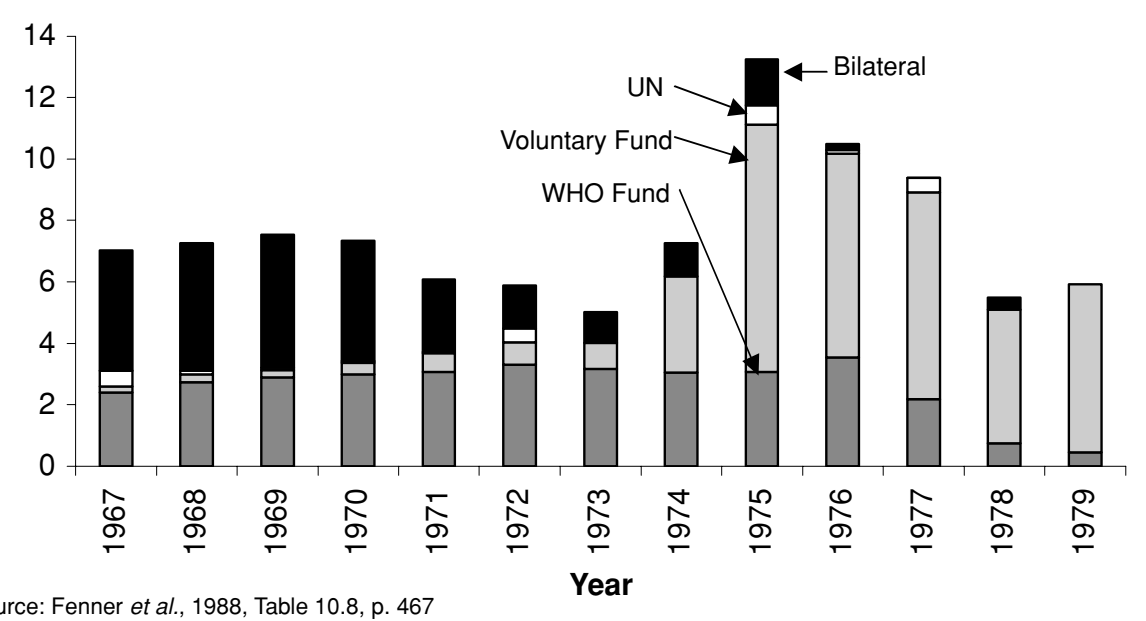

Fig. 2 International expenditure on smallpox eradication

391). And despite PAHO's help, by 1959 smallpox still circulated in Argentina, Bolivia, Brazil, Colombia, Ecuador, and Paraguay (Fenner et al., 1988, Table 9.6, pp. 396-397). More importantly, smallpox remained endemic in 34 African and 19 Asian countries. ${ }^{20}$ By the end of this period, the evidence was clear: smallpox eradication was not going to occur spontaneously, at least not any time soon. In the language of game theory, eradication was not the unique Nash equilibrium of the smallpox eradication game.

From 1959 to 1966, the declaration to eradicate coupled with the failure to provide the resources needed to achieve this goal suggests that countries perceived eradication to be a coordination game. In a coordination game, two outcomes can be supported as Nash equilibria (in pure strategies). For smallpox, these would be the outcome in which the disease is only controlled locally (the outcome realized in the earlier period) and (as demonstrated later in this paper) the mutually preferred outcome in which the disease is eradicated. To shift countries toward the second equilibrium would require a change in expectations, and this may have been the intention of the declaration - to assure the remaining endemic states that all other countries really would eliminate the disease. If all countries believed this, and if every country's eradication dividend were large enough relative to its cost, then each country could be relied upon to eliminate smallpox within its borders, and the disease would thus be eradicated worldwide. As matters turned out, coordination probably did have an effect. Smallpox transmission was interrupted in about 29 countries between 1959 and 1966. However, in 1966 smallpox remained endemic in about 31 countries. It seems that coordination was not enough. The reasons are explored in Section 5.

From 1967 to 1979, a different game was played. As the Assistant Director General of the WHO said on the day that the intensified program was approved, "Without a greatly intensified and well coordinated effort, and substantial additional resources (emphasis added), global eradication was not a realistic goal in the foreseeable future." 21 The game was now perceived to be one of the industrialized countries financing elimination in the remaining endemic countries. This game is the main focus of my inquiry.

\footnotetext{
${ }^{20}$ Excluding China, which was not a member of the WHO at this time. It was later learned that the mainland eliminated smallpox unilaterally in 1961.

${ }^{21}$ World Health Assembly (1966: 260).
} 


\section{Research, technology development, and learning by doing}

Before turning to the financing game, it is as well to note that other public goods underpinned the eradication program. Research was needed - to demonstrate the feasibility of eradication, and to show how eradication could be achieved. Crucially, eradication was only worth attempting if it could be shown that there did not exist a non-human host for the variola virus (an earlier attempt to eradiate yellow fever had to be abandoned after the discovery of a jungle reservoir for the disease). Much of this research was undertaken by research institutes based in the United States, the USSR, Japan, Britain, the Netherlands, India, Bangladesh, and Pakistan, with the WHO playing only a supporting role (Fenner et al., 1988: 479). It was also essential to know whether other orhopoxviruses (like monkeypox ${ }^{22}$ ) might mutate into a virus resembling variola. Being more generic in nature, this research was largely funded by the WHO (Fenner et al., 1988: 482).

A number of technical innovations aided the eradication effort. Most important was the development of the bifurcated needle by Wyeth Laboratories in the early $1960 \mathrm{~s}$ (Wyeth waived royalties for needles manufactured under contract with the WHO), which allowed vaccine to be administered even by the "illiterate vaccinator" (Fenner et al., 1988: 568-878). Further research by the WHO showed that, by increasing the carbon content of the steel, the needle could be reused (after sterilization by boiling) many times over. Both innovations lowered the cost of mass vaccination in the poorest countries.

Eradication was originally to be achieved by mass vaccination (at least 80 percent) of the population of each endemic country, combined with a system of surveillance and additional vaccination in the immediate vicinity of an outbreak (Fenner et al., 1988: 410-411). Initially, surveillance and containment were believed to be of greatest utility after mass vaccination (Fenner et al., 1988: 876). Experience in Nigeria, however, led to an important discovery. Smallpox was observed to spread more slowly than expected, and outbreaks tended to be both geographically and seasonally clustered - a result confirmed elsewhere in Africa as well as in Brazil and Indonesia (Hopkins, 1983: 305). From 1968, eradication efforts shifted towards an intensification of surveillance at the low point in the seasonal cycle and containment in the areas where outbreaks were observed to occur (Fenner et al., 1988: 877-878). This shift in strategy substantially lowered the costs of eradication. ${ }^{23}$ Further research sponsored by the WHO demonstrated that infants could be vaccinated safely, and that revaccination was of little additional benefit. This is just one example of a larger phenomenon: each step in the process provided knowledge that lowered the costs of taking the next steps.

\section{Eradication incentives in the South}

What were the economics of control and elimination in the South? Table 2 presents estimates of the annual cost of smallpox to India. ${ }^{24}$ This is a cost that would be avoided if the disease

\footnotetext{
${ }^{22}$ Monkey pox can be transmitted to humans but occurs only rarely in humans and has a basic reproduction rate of less than one in human populations. See Fenner (1993).

${ }^{23}$ Mass vaccination may also have made the surveillance-containment (or "ring" vaccination) strategy more effective. See Anderson and May (1991: 90).

${ }^{24}$ Differences in the estimates are hard to reconcile. Fenner et al.'s (1988) calculations are based partly on Ramaiah's (1976) estimates, which are not referenced by Brilliant (1985). Furthermore, Fenner et al. (1988) do not mention Brilliant's estimates, even though they refer to his work elsewhere. Though Brilliant underestimates benefits by excluding vaccination costs under a control program (the alternative to elimination), the major 
Table 2 Benefits of smallpox eradication to India (Millions of US dollars)

\begin{tabular}{lccc}
\hline & Brilliant (1985) & Fenner et al. (1988) & Ramaiah (1976) \\
\hline Avoided costs for medical services: & & & \\
$\quad$ Vaccination & & 10 & 10 \\
$\quad$ Care for smallpox patients & 53 & 12 & 1 \\
Indirect costs, loss of productivity & 97 & 700 & 80 \\
Total & 150 & 722 & 91 \\
\hline
\end{tabular}

Notes: The Fenner et al. (1988: Table 31.1, p. 1364) estimates are derived partly from Ramaiah (1976), who uses data for 1973-75. Brilliant's (1985) estimates are based on data for the period 1970-1973. The estimates for Ramaiah (1976: 199) are calculated for a 12-month period

were eradicated, thus serving as an estimate of the annual benefit of eradication to India. In addition to these estimates, Brilliant (1985) has calculated the annual costs of the eradication campaign, including indirect costs (lost productivity due to adverse reactions to vaccination) and opportunity costs (health workers being diverted from other programs). According to his calculations, the eradication program cost India about $\$ 17$ million a year during the campaign, a fraction of the annual benefits of eradication (by Brilliant's calculations, $\$ 150$ million). Though the benefit estimates by Fenner et al. (1988) are much larger, and those of Ramaiah (1976) smaller, all three studies draw the same (qualitative) conclusion: smallpox eradication was a very good deal for India. ${ }^{25}$

Indeed, India decided to eliminate smallpox just one month after the World Health Assembly voted to eradicate the disease globally in 1959, suggesting that there were coordination incentives. The attempt failed, however, for administrative and other reasons. ${ }^{26}$

The initial aim of the program was to vaccinate at least 80 percent of the population - the critical threshold thought sufficient to eliminate the disease - and yet a follow up study found that actual vaccination rates fell far short of this goal. ${ }^{27}$ India's decentralized system of government, comprising a large number of states, administrative districts, and villages, was poorly suited to implementing a national goal. Vaccination was compulsory in some states but not in others, and vaccinators were poorly supervised everywhere. To fulfill a quota, people who were easy to round up, such as schoolchildren, were often vaccinated more than once, while others - especially the very young and the very poor - were not vaccinated at all. Pilgrims, beggars, and itinerant laborers - key transmitters of disease - easily slipped through the vaccination net (Hopkins, 1983: 157). Many people deliberately evaded vaccination - to be

difference between his estimates and Ramaiah's is for the category “indirect costs." Brilliant and Ramaiah both estimate the value of a life lost based on expected years lost per death and the value per year as measured by national income. Ramaiah, however, subtracts consumption from income, giving a value per life lost of about $\$ 845$ (according to Fenner et al. (1988: 1365), \$825). Brilliant relies on GNP per capita alone (about \$110), and obtains a value per life lost of about $\$ 4,356$. Even more important may be the estimates of the number of deaths avoided by eradication. Brilliant assumes an average death toll of 22,036, while Ramaiah assumes an average mortality rate of about 94,000. The estimates presented in Fenner et al. (1988), by contrast, imply a death toll of nearly 850,000 per year (this is found by dividing total indirect costs, $\$ 700$ million, by the value per life, \$825). The actual number of reported deaths for 1967 was 26,225 (Fenner et al., 1988, Table 15.4, p. 724). It thus seems that Fenner et al. (1988) assume a much greater rate of under-reporting than Ramaiah (1976), who in turn assumes a higher rate than Brilliant (1985).

${ }^{25}$ Basu et al. (1979: 312) present estimates identical to those in Ramaiah (1976), but without giving attribution.

${ }^{26}$ See Brilliant (1985), Basu et al. (1979), and Fenner et al. (1988), Chapter 15.

${ }^{27}$ Making matters even worse, epidemiological studies later showed that high population density in India would likely require immunization rates in excess of 80 percent, at least in urban areas; see Anderson and May (1991: 89-90). 
spared the painful rotary lancet and a possible reaction to the vaccine, or to avoid upsetting the Hindu goddess, Shitala mata. Surveillance was also spotty, and many outbreaks went unrecorded. Compounding these problems, local supervisory staff under-reported cases for fear that evidence of an outbreak would expose their incompetence, while villagers concealed infected persons, to prevent them from being taken by force to distant, ill-equipped hospitals. As well, vaccines produced in state laboratories were in short supply; and a poor refrigeration infrastructure meant that the heat sensitive vaccine was often damaged (Basu et al., 1979: 102). ${ }^{28}$

A careful reading of the history of India's elimination effort suggests that India had an incentive to eliminate smallpox unilaterally. ${ }^{29}$ What it lacked was organizational capacity. As explained by a member of the Indian eradication staff years after smallpox had been eliminated in India, it was not "the quantum of money spent but rather the manner of doing it which made all the difference between success and failure" (see Fenner et al., 1988: 789). Indeed, China, with a similar income per head as India, and a population almost 50 percent greater, aimed to eliminate smallpox as early as 1949 - and finally succeeded in the early 1960s without international assistance. China's mass vaccination campaigns, unlike India's, were extremely well organized. A first visit to a village by health authorities succeeded in vaccinating nearly 90 percent of the local population, more than the minimum needed to eliminate the disease. The communist leadership of China even created incentives to promote vaccination. After communes were established in 1958, for example, "monthly payments by the State were linked to evidence of vaccination of the family head and family members" (Fenner et al., 1988: 342).

\section{Static analysis}

It will prove helpful to begin by looking at the financing game from a static perspective (I consider the dynamics of financing in Section 9). I take it that the amount of money needed to increase control in the remaining endemic countries to a level sufficient to eradicate the disease globally is a given; denote this amount $\bar{M}$. I take it also that this amount needs to be supplied by the industrialized countries; otherwise eradication will fail. ${ }^{30}$ Suppose, then, that there are $N$ industrialized countries, and denote the money offered by country $i, m_{i}$. The sum of contributions is $M=\sum_{i=1}^{N} m_{i}$. Country $i$ will then receive a payoff

$$
\begin{aligned}
& \Pi_{i}=-m_{i} \quad \text { if } M<\bar{M}, \\
& \Pi_{i}=-m_{i}+v_{i} \quad \text { if } M \geq \bar{M},
\end{aligned}
$$

where $v_{i}$ is $i$ 's eradication dividend. Notice that contributions are assumed to be of no value to any industrialized country if the threshold $\bar{M}$ is not met. Since the disease is already

\footnotetext{
${ }^{28}$ A single decision by the WHO's Smallpox Eradication Unit - to switch from liquid to freeze-dried vaccine - increased vaccine efficacy from 80 to 95 percent; see Fenner et al. 1988: 728.

${ }^{29}$ Note, however, that India also had other health priorities. According to Brilliant (1985: 33), "for India's health planners, occupied then by emergencies and competing political demands on scarce resources, the longterm benefits from disease eradication were not a great motivation. Health planners are sensitive to immediate political realities, and the benefits of smallpox eradication would be realized only at some future time when the \$3 million annual expenditures for smallpox could be applied to other health problems. In the meantime, however, the cost of putting so many scarce resources into one program rather into many health needs was high."

${ }^{30}$ This amount of money can be interpreted as the "incremental cost" of eradication. It can be determined endogenously in a model of international cooperation with strongly asymmetric countries; see Barrett (2001). 
eliminated in the North, the benefit to $i$ of further controls short of eradication is zero. Notice also that (1) assumes that contributions, once made, are sunk. I shall discuss this assumption later. Finally, let $V=\sum_{i=1}^{N} v_{i}$ and assume $V>\bar{M}$ (eradication is globally efficient).

In general, there may exist a multiple of equilibria. ${ }^{31}$ If $v_{i}<\bar{M} \forall i$, then no country would want to contribute if no other country contributed, making $m_{i}=0 \forall i$ a Nash equilibrium. If, to the contrary, $v_{i}>\bar{M} / N \forall i$, then $m_{i}=\bar{M} / N \forall i$ would be a Nash equilibrium. Obviously, it is possible for both of these conditions to hold simultaneously, and so there may exist two symmetric equilibria (in pure strategies). There may also exist a large number of asymmetric equilibria in which some countries contribute more than others. Suppose, for example, that $v_{1}>\bar{M}>v_{2}>v_{3}>\ldots>v_{N}$. Then $v_{1}=\bar{M}, v_{2}=v_{3}=\ldots=v_{N}=0$ would be a Nash equilibrium. Of course, there would also exist many other Nash equilibria to this game in which many if not all countries made positive contributions.

Fenner et al. (1988: 409) claim that, if the intensified eradication effort were to succeed "additional resources would be required, but it was apparent that voluntary contributions alone would not suffice." This suggests that $m_{i}=0 \forall i$ was a Nash equilibrium of the static game. As just shown, however, this could only be true if $v_{i}<\bar{M} \forall i$. Other information supplied by Fenner et al. implies that this was not true. I discuss this in Section 8.

\section{Experimental evidence}

How do people actually play games of this type? Cadsby and Maynes (1999) conducted experiments for variations of the static game analyzed above, assuming $v_{i}>\bar{M} / N \forall i$ and $v_{i}<\bar{M} \forall i{ }^{32}$ The games were played by 22 different sets of people, each set consisting of ten persons. In each game, players had to choose voluntary contributions to a threshold public good. Specifically, each player was given a quantity of tokens, which could either be contributed or hoarded. Fractional contributions were allowed, making contributions continuous. Each player received a payoff that depended on his own contribution and the contributions of others. If the aggregate of all contributions exceeded a specified threshold, every player got a reward (independent of the amounts contributed individually). For the games of greatest interest to the smallpox case, contributions were not returned, even if the threshold had not been met or if an excess of tokens had been contributed (the costs of contributing were sunk). For each set of ten players, the game was played many times over. ${ }^{33}$ The game began anew each period (accumulated tokens could not be spent), but there was learning over time. ${ }^{34}$ The players were symmetric; for each game, every player was given the same quantity of tokens and received the same reward if the threshold was met. However, the levels of the reward and threshold varied across the different sets of players.

Several of Cadsby and Maynes's (1999) results are worth highlighting here. ${ }^{35}$ First, the public good was provided in only one out of every five plays of the game, suggesting that coordination around the collectively preferred Nash equilibrium is hardly automatic. Second, positive amounts were contributed even in the majority of the games in which the threshold

\footnotetext{
${ }^{31}$ I limit my attention here to pure strategy equilibria.

${ }^{32}$ Related experimental papers include Isaac, Schmidtz, and Walker (1989) and Suleiman and Rapoport (1992).

${ }^{33}$ For 22 of the groups, the game was played 25 times; for the other three it was played just 14 times.

${ }^{34}$ The real contributions game was played only once, but over a number of years.

${ }^{35}$ Another result in Cadsby and Maynes (1999) is discussed in Section 11.
} 
Table 3 Benefits of smallpox eradication to the United States, 1968 (Millions of US dollars)

\begin{tabular}{lr}
\hline & Amount \\
\hline Direct cost for medical services: & 92.8 \\
$\quad$ Vaccination & 0.7 \\
Treatment of complications & \\
Indirect costs, loss of productivity: & 41.7 \\
$\quad$ Work losses due to vaccination and reactions & 0.4 \\
Permanent disability due to complications & 0.1 \\
Premature death & \\
Cost of international traffic surveillance and & 14.5 \\
$\quad$ delays in clearance of vessels & 150.2 \\
Total & \\
\hline
\end{tabular}

Source: Sencer and Axnick (1973); see also Fenner et al. (1988), Table 31.2, p. 1365

was not met. ${ }^{36}$ This means that, while Nash equilibria may be strong attractors, they are not a sound basis for predicting the outcome of a particular play of a game. Third, there was substantial variation in outcomes among the different groups. Some groups were more cooperative than others. Finally, public goods with lower thresholds and higher rewards were more likely to be provided. This last result conflicts with the theory developed in Section 6 . As explained in Section 10, however, this result also may be important to understanding why the smallpox effort succeeded.

\section{Eradication incentives in the North}

The Cadsby-Maynes (1999) experiment is useful because it provides a different picture of the contributions game as compared with the analytical model. Like the analytical model, however, it also provides only a partial view. Contributions to the smallpox eradication effort involved many more players, and these were all asymmetric. Perhaps even more importantly, the Cadsby-Maynes (1999) experiment assumes $v_{i}<\bar{M} \forall i$, and as explained below, this assumption did not hold for the smallpox eradication game.

Estimates reported in Sencer and Axnick (1973), and reproduced in Table 3, suggest that eradication would save the US about $\$ 150$ million a year in avoided vaccination costs. ${ }^{37}$ Assuming a three percent discount rate (and ignoring growth in population and incomes), the value of $v$ for the United States, as suggested by the estimates in Table 3, would be about $\$ 5$ billion. Since the total of international transfers needed to achieve eradication was just under $\$ 100$ million, it appears that the US had a strong incentive to fund the eradication effort unilaterally. ${ }^{38}$ This in turn implies that, in the static contributions game, $m_{i}=0 \forall i$ was not a Nash equilibrium.

\footnotetext{
${ }^{36}$ Given the contribution levels of other countries, each country will either contribute nothing or an amount just sufficient to meet the threshold. Positive contributions short of the threshold are not a Nash equilibrium.

${ }^{37}$ The reasoning behind the valuations used in these calculations is not explained by Sencer and Axnick (1973). Fenner et al. (1988: 1365) extrapolate from this value, estimating that the annual savings to other industrialized countries would be around $\$ 350$ million. This implies that the US accounted for about 30 percent of the total benefit of eradication to the North.

${ }^{38}$ Indeed, according to Fenner et al. (1988: 1365), the US, "although the largest donor, is estimated to realize in savings the total of all its contributions to the programme every 26 days" (see also Brilliant, 1985: 134). This estimate of the return on investment is still quoted today; see Section 12.
} 
And yet it is not obvious that countries would be assured of financing the eradication effort fully. The greed factor in the provision of this public good would make players hold back their contributions. ${ }^{39}$ This suggests that countries would need to coordinate their voluntary contributions. That is, they would need to agree - implicitly if not explicitly - on a burdensharing rule. I shall return to this issue in Section 11, but first I reconsider the nature of the financing game.

\section{Dynamic analysis}

Section 6 assumed that countries had just one opportunity to choose their contribution levels. The smallpox game was different. Countries could distribute their contributions over time, all the while observing the contributions made by others in the past. Since contributions, once made, were sunk, contributing a large amount up front made a donor vulnerable. Other countries might respond to a large donation by lowering their contributions, knowing that the large donor would then have an incentive to contribute yet more to ensure that the public good was provided. Anticipating this, every country might therefore want to limit its perperiod contribution, waiting to see whether the other countries reciprocated before deciding to contribute yet more (Schelling, 1960: 45).

Admati and Perry (1991) confirm that players may want to contribute in small steps rather than all at once, but Compte and Jehiel (2003) show that, if players are asymmetric, then contributions should be made without substantial delay. While the equilibria of these models differ as regards sequencing, both papers support the basic result of the static game, that full financing should have been the unique equilibrium of the smallpox eradication game. ${ }^{40}$ However, neither model explains why the US should have financed smallpox elimination from 20 contiguous African states early in the game, or why so many states should have supported mandatory contributions after this time. ${ }^{41}$ Other research suggests that these contributions may have been strategic.

\footnotetext{
${ }^{39}$ Cadsby and Maynes (1998) report the results of experiments of corporate takeovers in which there exist only efficient pure strategy Nash equlibria - just as in the case of a public goods game with $v_{i}>\bar{M}$. In this paper, shares of a company are worth $P_{0}$, and a raider offers shareholders a price $P_{b}>P_{0}$ to effect a takeover. Once the raider obtains a threshold quantity of shares, the takeover succeeds and the share price jumps to $P_{1}$ $>P_{b}$. As in the contributions game with $v_{i}>\bar{M}$ for some $i$, attainment of the required threshold is a strong attractor, and yet the interests of the players are not consonant. In the takeover game, though every player wants the raider to succeed, each player would prefer that others tender a majority of shares. This is very similar to the public goods game but the incentives to tender shares are particularly strong because an investor cannot lose by doing so. By contrast, a country that contributes to smallpox eradication will receive no benefit unless the threshold contribution is received and the entire effort succeeds. Still, even under these more favorable circumstances, Cadsby and Maynes (1998: 548) find that offers do not "converge exactly to a pure-strategy equilibrium, and stay put. Rather the number of tokens exchanged tends to cycle around the [threshold]."

${ }^{40}$ For the linear model developed here, Admati and Perry (1991) show that the public good will only be provided if $v_{i}>\bar{M}$ for some $i$. Their analysis thus implies that this condition was even more important than suggested by the static model. However, Compte and Jehiel (2003) show that, if the players are asymmetric, then the equilibrium of the contributions game will always be Pareto efficient.

${ }^{41}$ The Compte-Jehiel model predicts that the US, being the country that benefits most from eradication, and having a benefit many times greater than the cost, should have fully financed the eradication program, and done so by making a single contribution up front. The US did make a large contribution up front, but it contributed more later, and was certainly not the only country to finance the eradication effort.
} 


\section{Strategy}

Suppose that $v_{1}>v_{2}>\cdots>v_{N}$. Then, letting the US be country 1, it is plain that the US could gain by preempting the other countries - by committing to contribute an amount $\bar{m}_{1}, \bar{m}_{1}<v_{1}$, provided $v_{2} \geq \bar{M}-\bar{m}_{1}$ (Andreoni, 1998). If the US made this contribution, and could commit not to contribute any more, then it could limit its overall contribution, while ensuring that eradication was fully financed. ${ }^{42}$

Though this reasoning can explain why the US would have wanted to contribute a large amount up front, it cannot explain why the US should have contributed more later on (the US ended up donating over $\$ 6$ million in cash and \$1 million in kind on top of its initial bilateral donation and its mandatory contributions to the special account). In any event, the history of this case reveals a different explanation. According to Fenner et al. (1988: 850), "the USA's decision to contribute to [the eradication program] did not result from a considered policy judgment to support the WHO Intensified Program as such.” Instead, US support for smallpox eradication in Africa grew out of an earlier plan by the US Agency for International Development (USAID) to control measles in 11 African countries. D. A. Henderson, who was Chief of Surveillance at the Centers for Disease Control (CDC) at this time, objected to the USAID plan, arguing that the measles program should be augmented by an effort to eliminate smallpox from the entire region. Smallpox elimination, he reasoned, stood a better chance of providing a long-term benefit to the region, and "a successful regional effort in one of the most highly endemic areas would represent an important contribution [to the global eradication effort] and perhaps a stimulus to other endemic countries" (Fenner et al., 1988: 855). USAID rejected Henderson's proposal, but then luck intervened. As Henderson later explained, "The standoff broke unexpectedly. [President] Johnson wanted to announce some US initiative relative to 'International Cooperation Year'; the smallpox-measles proposed plan (bypassing USAID) appeared on the table; it appealed to the [White House] group making the decision; and USAID was ordered to put up the money ...."43 In short, the substantial bilateral aid offered by the US - aid that breathed life into the entire eradication effort - was made neither for strategic reasons (to get a bandwagon of international assistance going) nor even for reasons of self-interest. It seems rather to have been motivated only for reasons of political expediency.

Can theory explain why the WHO Director-General proposed mandatory contributions far short of the total international assistance needed? These contributions could also be interpreted as being strategic (Andreoni, 1998). Denote the sum of these contributions by $T$ and assume that $T<\bar{M}$ (recall that the mandatory contributions were only about a third of the amount budgeted for international finance). Then, if $\bar{M} \geq v_{1} \geq \bar{M}-T$, the mandated contributions would ensure that failure to eradicate would no longer be a Nash equilibrium. Eradication would be assured (though the distribution of voluntary contributions would remain indeterminant). Once again, however, history points to a different interpretation. As shown previously, the economics of eradication already favored unilateral provision by the United States, even if no other country contributed. Thus, the mandated contributions should not have made any difference as regards the final outcome.

\footnotetext{
$\overline{42}$ Vesterlund (2003) offers a different explanation for such contributions. In her model, the giving of "seed money" serves as a signal of quality, causing donors who are less informed about the prospects of success to donate more.

${ }^{43}$ Personal communication, 24 September 2003.

Springer
} 
While theory cannot easily explain either the initial contribution by the US or the mandated contributions voted on by the World Health Assembly, both actions did lower the threshold required for voluntary contributions - and the Cadsby-Maynes (1999) experiment showed that lowering this threshold would likely increase the chance that the threshold would be met and the public good supplied. In a related paper, List and Lucking-Reiley (2002) report the results of a field experiment in which contributions were observed to increase in the amount of seed money supplied. Perhaps Fenner et al. (1988: 1350) were right after all that the mandated contributions were "an important stimulus without which eradication could not have been achieved."

\section{Burden sharing}

Deciding which countries should contribute, and by how much, is a bargaining problem. Though it may be in the interests of a single country to pay the full cost of international finance, given that other countries contribute nothing, many other equilibria of the burden sharing game are possible. ${ }^{44}$ Public goods experiments suggest that contributions often reflect concerns for fairness and not only self interest, and fairness would seem to demand that eradication costs be shared, perhaps in proportion to the benefits received. ${ }^{45}$

Cadsby and Maynes's (1999) public goods experiment supports this reasoning. In their experiment, players were symmetric, and so the obvious fair burden sharing arrangement was for each player to contribute $1 / N$ th of the threshold amount. Cadsby and Maynes (1999) failed to observe any group playing the symmetric equilibrium exactly. However, when the public good was provided, a number of players offered the symmetric equilibrium amounts, and others offered contributions close to these amounts. By contrast, when the public good was not provided, players tended to deviate more from these symmetric values. Though Cadsby and Maynes (1999) do not formally test the hypothesis that contributions may reflect concerns for fairness, it seems that cooperation may break down if enough players deviate enough from their fair, focal contributions. Moreover, this may be true even if failure to supply the public good is self-damaging (that is, even if $v_{i}>\bar{M}$ for some $i$; see, for example, Fehr \& Gächter, 2000).

For the smallpox campaign, the obvious focal point for a "fair" sharing of the burden was the WHO's scale of assessments. Other global public health measures were financed according to the same arrangement, as was the special fund for smallpox eradication. Indeed, the alternative budgets proposed by France and the United States differed only with respect to the total amounts to be raised, not the burden-sharing formula. In addition to precedent, the assessments also reflect the benefits received (the assessments increase in population; see Table 4) and ability to pay (the assessments also increase in income per head for given

\footnotetext{
${ }^{44}$ I am referring here to the static contributions game, though the same would be true of the AdmatiPerry (1991) model. In the Compte and Jehiel (2003) framework, even tiny variations in country valuations would support very different equilibria. As a prediction of how real countries behave, this seems implausible.

${ }^{45}$ Olson (1965) reasoned that contributions would likely be in proportion to the benefits received - an observation explored empirically by Olson and Zeckhauser (1966) in their analysis of the financing of NATO.
} 
Table 4 Indices of country characteristics and voluntary contributions

\begin{tabular}{|c|c|c|c|c|}
\hline Country* & GDP PC & Population & Assessment & Contribution \\
\hline United States & 100.00 & 100.00 & 100.00 & 100.00 \\
\hline Switzerland & 93.86 & 2.97 & 2.78 & 1.49 \\
\hline Canada & 83.68 & 10.45 & 9.66 & 10.03 \\
\hline Sweden & 80.69 & 3.83 & 3.87 & 62.82 \\
\hline Australia & 80.34 & 6.28 & 4.86 & 0.13 \\
\hline Luxembourg & 74.22 & 0.17 & 0.16 & 0.03 \\
\hline Denmark & 73.85 & 2.36 & 2.02 & 4.34 \\
\hline F.R. Germany & 72.01 & 28.85 & 23.17 & 2.02 \\
\hline France & 71.80 & 24.48 & 19.25 & 0.00 \\
\hline New Zealand & 71.48 & 1.40 & 1.04 & 0.04 \\
\hline Netherlands & 70.97 & 6.32 & 3.93 & 11.22 \\
\hline United Kingdom & 65.96 & 26.40 & 19.19 & 4.09 \\
\hline Norway & 66.94 & 1.86 & 1.41 & 4.00 \\
\hline Belgium & 65.84 & 4.59 & 3.49 & 1.52 \\
\hline Finland & 62.68 & 2.21 & 1.45 & 0.44 \\
\hline Austria & 60.99 & 3.54 & 1.83 & 0.30 \\
\hline Iceland & 59.31 & 0.10 & 0.11 & 0.00 \\
\hline Italy & 58.49 & 25.82 & 10.70 & 0.00 \\
\hline Trinidad \& Tobago & 57.87 & 0.47 & 0.12 & 0.00 \\
\hline Japan & 57.13 & 51.22 & 18.19 & 2.54 \\
\hline Venezuela & 55.40 & 5.61 & 1.33 & 0.00 \\
\hline Saudi Arabia & 48.64 & 3.19 & 0.30 & 0.80 \\
\hline Israel & 47.88 & 1.54 & 0.66 & 0.00 \\
\hline Spain & 47.42 & 16.47 & 3.38 & 0.00 \\
\hline Argentina & 41.73 & 11.93 & 2.83 & 0.05 \\
\hline Ireland & 39.75 & 1.46 & 0.49 & 0.00 \\
\hline Iraq & 38.28 & 4.91 & 0.22 & 0.00 \\
\hline Iran & 36.98 & 14.84 & 0.80 & 3.50 \\
\hline Barbados & 36.14 & 0.11 & 0.10 & 0.00 \\
\hline Greece & 34.60 & 4.26 & 0.98 & 0.09 \\
\hline USSR & 34.21 & 117.80 & 52.01 & 35.26 \\
\hline Gabon & 33.06 & 0.28 & 0.11 & 0.00 \\
\hline Mexico & 32.63 & 26.54 & 2.74 & 0.00 \\
\hline Singapore & 31.90 & 0.96 & 0.18 & 0.00 \\
\hline Uruguay & 30.04 & 1.33 & 0.23 & 0.00 \\
\hline Cyprus & 29.13 & 0.29 & 0.11 & 0.00 \\
\hline Portugal & 28.66 & 4.29 & 0.52 & 0.00 \\
\hline Yugoslavia & 28.64 & 9.91 & 1.21 & 0.10 \\
\hline Chile & 25.10 & 4.72 & 0.60 & 0.00 \\
\hline Namibia & 24.46 & 0.45 & 0.01 & 0.00 \\
\hline Mauritius & 23.74 & 0.41 & 0.10 & 0.00 \\
\hline South Africa & 23.67 & 11.62 & 1.64 & 0.00 \\
\hline Costa Rica & 23.02 & 0.89 & 0.11 & 0.00 \\
\hline Brazil & 22.27 & 48.78 & 2.84 & 0.52 \\
\hline Syria & 22.02 & 3.30 & 0.12 & 0.00 \\
\hline Fiji & 21.71 & 0.26 & 0.05 & 0.00 \\
\hline Czechoslovakia & 21.07 & 6.92 & 3.00 & 0.16 \\
\hline Suriname & 20.91 & 0.17 & 0.01 & 0.00 \\
\hline Malta & 20.72 & 0.16 & 0.11 & 0.00 \\
\hline
\end{tabular}


Table 4 (Continued)

\begin{tabular}{|c|c|c|c|c|}
\hline Country* & GDP PC & Population & Assessment & Contribution \\
\hline Peru & 20.60 & 6.81 & 0.28 & 0.01 \\
\hline Panama & 19.75 & 0.78 & 0.11 & 0.00 \\
\hline Jamaica & 19.47 & 0.92 & 0.13 & 0.00 \\
\hline Turkey & 18.54 & 18.01 & 1.06 & 0.00 \\
\hline Malaysia & 18.14 & 5.53 & 0.32 & 0.00 \\
\hline Swaziland & 17.69 & 0.22 & 0.03 & 0.00 \\
\hline Nicaragua & 17.26 & 1.08 & 0.10 & 0.00 \\
\hline Colombia & 17.17 & 10.77 & 0.58 & 0.01 \\
\hline Ecuador & 16.96 & 3.15 & 0.12 & 0.00 \\
\hline Guatemala & 15.90 & 2.70 & 0.14 & 0.00 \\
\hline Jordan & 15.76 & 0.91 & 0.11 & 0.00 \\
\hline Korea & 15.37 & 15.99 & 0.39 & 0.00 \\
\hline Algeria & 15.36 & 7.17 & 0.30 & 0.00 \\
\hline El Salvador & 14.40 & 1.83 & 0.11 & 0.00 \\
\hline Guyana & 14.20 & 0.33 & 0.10 & 0.00 \\
\hline Papua NG & 13.41 & 1.23 & 0.02 & 0.00 \\
\hline Domin. Rep & 13.04 & 2.27 & 0.11 & 0.00 \\
\hline Tunisia & 12.91 & 2.57 & 0.12 & 0.00 \\
\hline Ivory Coast & 12.79 & 2.98 & 0.11 & 0.00 \\
\hline Bolivia & 12.78 & 2.21 & 0.11 & 0.00 \\
\hline Thailand & 11.85 & 18.48 & 0.40 & 0.01 \\
\hline Congo & 11.63 & 0.62 & 0.11 & 0.00 \\
\hline Paraguay & 11.60 & 1.21 & 0.11 & 0.00 \\
\hline Philippines & 11.18 & 19.29 & 0.83 & 0.02 \\
\hline Morocco & 10.78 & 7.81 & 0.27 & 0.00 \\
\hline Mozambique & 9.74 & 4.80 & 0.02 & 0.00 \\
\hline Honduras & 9.48 & 1.38 & 0.11 & 0.00 \\
\hline Sri Lanka & 9.39 & 6.18 & 0.15 & 0.00 \\
\hline Egypt & 8.98 & 16.58 & 0.23 & 0.00 \\
\hline Sierra Leone & 8.38 & 1.34 & 0.11 & 0.00 \\
\hline Botswana & 8.37 & 0.33 & 0.02 & 0.00 \\
\hline Zimbabwe & 8.34 & 2.71 & 0.06 & 0.00 \\
\hline Senegal & 8.10 & 2.19 & 0.11 & 0.00 \\
\hline Zambia & 8.05 & 2.17 & 0.11 & 0.00 \\
\hline Benin & 7.80 & 1.36 & 0.11 & 0.00 \\
\hline Romania & 7.71 & 9.84 & 1.06 & 0.00 \\
\hline Madagascar & 7.59 & 3.45 & 0.11 & 0.00 \\
\hline Nigeria & 7.54 & 29.38 & 0.42 & 0.06 \\
\hline Bangladesh & 7.41 & 34.40 & 0.11 & 0.00 \\
\hline Liberia & 7.14 & 0.72 & 0.11 & 0.00 \\
\hline Ghana & 6.95 & 4.41 & 0.19 & 0.01 \\
\hline Pakistan & 6.92 & 31.71 & 0.84 & 0.00 \\
\hline Angola & 6.88 & 3.03 & 0.02 & 0.00 \\
\hline Mauritania & 6.62 & 0.62 & 0.11 & 0.00 \\
\hline Haiti & 6.36 & 2.25 & 0.11 & 0.00 \\
\hline Gambia & 6.30 & 0.24 & 0.06 & 0.00 \\
\hline Cameroon & 6.20 & 3.36 & 0.11 & 0.00 \\
\hline Indonesia & 6.19 & 59.97 & 0.86 & 0.00 \\
\hline Somalia & 6.18 & 2.13 & 0.11 & 0.00 \\
\hline
\end{tabular}


Table 4 (Continued)

\begin{tabular}{lcccc}
\hline Country* & GDP PC & Population & Assessment & Contribution \\
\hline India & 5.73 & 277.84 & 4.60 & 2.02 \\
Kenya & 5.67 & 6.11 & 0.11 & 0.67 \\
Nepal & 5.33 & 5.82 & 0.11 & 0.00 \\
Central African R. & 5.26 & 0.94 & 0.11 & 0.00 \\
China & 5.16 & 412.18 & 15.07 & 0.00 \\
Guinea-Bissau & 5.16 & 0.29 & 0.02 & 0.00 \\
Niger & 5.01 & 2.13 & 0.11 & 0.00 \\
Comoros & 4.97 & 0.13 & 0.01 & 0.00 \\
Lesotho & 4.80 & 0.54 & 0.09 & 0.00 \\
Chad & 4.72 & 1.84 & 0.11 & 0.00 \\
Rwanda & 4.56 & 1.95 & 0.11 & 0.00 \\
Uganda & 4.51 & 5.04 & 0.11 & 0.05 \\
Guinea & 4.48 & 1.99 & 0.11 & 0.07 \\
Zaire & 4.43 & 10.4 & 0.13 & 0.01 \\
Togo & 4.41 & 1.03 & 0.10 & 0.00 \\
Cape Verde & 4.17 & 0.13 & 0.01 & 0.00 \\
Malawi & 3.55 & 2.35 & 0.11 & 0.00 \\
Tanzania & 3.37 & 6.96 & 0.11 & 0.00 \\
Mali & 3.27 & 2.68 & 0.11 & 0.00 \\
Burundi & 3.18 & 1.69 & 0.11 & 0.00 \\
Myanmar & 3.05 & 13.70 & 0.14 & 0.00 \\
Burkina Faso & 2.95 & 2.83 & 0.11 & 0.00 \\
Ethiopia & 2.19 & 14.85 & 0.11 & 0.00 \\
\hline
\end{tabular}

Note: *Countries in italics, smallpox endemic between 1959 and 1966 but not from 1967. Countries in bold, smallpox endemic in 1967. All data presented as indices relative to US values. GDP PC is real GDP per capita in constant (1985) dollars using chain index, averaged over 1967-1979; Sources: Endemic countries from Fenner et al. (1988), Table 9.6.; real per capita income and population, averaged over the period 1967-1979, from Penn World Tables (Mark 5.6a) (http:datacentre2.chass.utoronto.ca/pwt): assessments averaged over the priod 1967-79 from the World Health Organization (http://policy.who.int). Contributions totals for 1967-79, Fenner et al. (1988), Table 10.6, p. 464

population; see again Table 4). ${ }^{46}$ For all these reasons the WHO scale would seem the natural focal point for funding the eradication effort. ${ }^{47}$

Indices of voluntary contributions and country assessments (with the US being given values of 100) are shown in the last two columns of Table 4, where countries are ordered according to their income per capita. Voluntary contributions include both bilateral assistance and donations to the WHO's special account for smallpox eradication. They also include both cash and in-kind contributions (just over 20 percent of the contributions to the special account were in kind), the latter of which are subject to measurement errors (the values attached to in-kind contributions - mainly, vaccine - were assigned by the donors themselves, and the

\footnotetext{
${ }^{46}$ The WHO's assessments are equal to the UN scale, corrected for differences in membership. The UN scale is derived in turn from national income (that is, income per head times population), adjusted for differences in income per capita. The WHO also establishes ceilings and floors. The ceiling - paid only by the US - was lowered over time (from 1967 to 1979, the WHO assessments for the US fell from 31.20 to 25.0 percent). Contributions by other countries are limited by the principle, adopted in 1955, that no country should be required to pay more per capita than the US. A floor applies to the world's smallest and poorest states. Initially fixed at 0.04 percent, the floor was lowered in stages, reaching 0.01 percent in 1979 .

${ }^{47}$ For the seminal discussion of the effect of focal points on bargaining outcomes, see Schelling (1960). 
estimates vary widely; see Fenner et al., 1988: 463-465). ${ }^{48}$ A correlation between assessments and contributions is plainly evident in these data. Nine of the ten richest countries (that is, countries with high assessments) made voluntary contributions, whereas none of the ten poorest countries (countries with low assessments) contributed. At the same time, however, there is substantial variation in the data. Some rich countries with high assessments, like France, did not contribute to the voluntary fund, while some poor countries with low assessments, such as Kenya, did contribute. Note, however, that care must be taken in interpreting these data. Kenya's contributions, for example, were all in kind (and therefore subject to greater measurement error). They also resulted from a "back-door agreement" in which the WHO financed Kenya's vaccine manufacturing plant in return for Kenya donating vaccine. ${ }^{49}$

The most striking outlier in these data is Sweden, which gave the largest donation relative to its assessment of any country. (In addition, Sweden's contributions were almost entirely in cash rather than in kind.) Sweden is famously charitable, and other experiments suggest that contributions to threshold public goods may have a cultural basis (Cadsby et al., 2003). However, in this case there appears to be another reason for Sweden's relative generosity. Most of Sweden's contributions followed specific appeals made at critical phases of the eradication campaign, when other countries were withholding support. Following an explosive epidemic that threatened to undermine the elimination effort in India in 1974, the WHO approached "numerous governments for additional finances" (Fenner et al., 1988: 768). Few showed any interest, however, "and no country indicated it was in a position to act quickly in answering an appeal" (Fenner et al., 1988: 768). A major reason for this may have been doubt about the program's prospects of success. Smallpox incidence in India shot up in the spring of 1974, reaching levels not seen for nearly two decades. And potential donors had fresh memories of an earlier failure.

As observed by Fenner et al. (1988: 768), "WHO's frequent appeals in the past for funds to bolster its malaria eradication campaign, and the continuing setbacks in that programme despite infusions of ever larger sums of money, were well remembered." As chance would have it, however, a WHO official learned, "in a casual conversation," that Sweden was examining options for redirecting assistance after the cancellation of a development project in India (Fenner et al., 1988: 768). Discussions promptly followed with a senior representative of the Swedish embassy in New Delhi, who became "convinced as few others were, that an effective and well-directed campaign was in progress whatever the smallpox incidence might suggest" (Fenner et al., 1988: 769). The diplomat persuaded his superiors in Stockholm of the merits of the program, and within a few weeks, Sweden gave $\$ 2.8$ million to the WHO to support smallpox elimination in India - a sum later increased to $\$ 10$ million. ${ }^{50}$

\footnotetext{
${ }^{48}$ According to Fenner et al. (1988: 465), "most vaccine was valued at US\$10-16 per 1000 doses but values as high as US\$256 per 1000 doses were assigned by some donors. The average value for all vaccine contributed worked out at US\$17 per 1000 doses, although estimates of the actual costs of vaccine production in the industrialized countries in the early 1970s were in the range of US\$30-40 per 1000 doses."

${ }^{49}$ Personal communication, D.A. Henderson, 24 September 2003. Elsewhere, Fenner et al. (1988: Table 11.15, 563) show that France donated 200,000 doses of vaccine. The latter Table is for the years $1967-$ 1984, whereas the data in Table 5 is for 1967-1979. Presumably, the donations were made after smallpox eradication had been certified. Note also that France administered smallpox vaccination in French Equatorial Africa (comprising Cameroon, the Central African Republic, Chad, Congo, and Gabon) in the early 1960s, lowering the number of cases to just two by 1966, the start of the intensified campaign. See Fenner et al. (1988: 906-907).

${ }^{50}$ Self-interest may also have been a motivation. Sweden eliminated smallpox in 1895 - the first country in the world to do so - and yet, like all other countries in Europe, remained vulnerable to imports. In 1963, a Swedish 
Even including outliers, were actual contributions correlated with the assessment scale? To test this hypothesis, I calculated the Kendall correlation coefficient (also known as tau). ${ }^{51}$ This measures the correlation between two rank measures - determining whether each pair of observations is concordant (track positively) or discordant (negatively), taking the difference between the number of concordant and discordant pairs, and then normalizing to yield a value between -1 and +1 . Because there are many ties for both the contributions assessment variables, a specific variant of tau, known as tau-b, is the appropriate measure of correlation. For the data shown in Table 4 , tau-b $=0.5230$. Though tau-b does not have a ready interpretation, a test of the null hypothesis of zero association is rejected at the one percent significance level. ${ }^{52}$ Statistical analysis thus overwhelmingly supports the hypothesis that the assessments proved a strong attractor for voluntary contributions. However, as was observed in the Cadsby-Maines (1999) experiments, the attraction was not strong enough to deter all free riding behavior.

\section{Politics}

With the advantage of hindsight, the difficulty of financing smallpox eradication is perhaps easier to understand. When eradication was first attempted, it was not known with certainty that it could succeed. Nor was it known with certainty exactly how costly eradication would ultimately prove to be. Moreover, the massive effort to eradicate malaria had already eaten up substantial resources, and was foundering even as the smallpox eradication effort was first launched. It seems, however, that these considerations cannot offer more than a partial explanation because funding was stingy even after smallpox had been eliminated everywhere but the horn of Africa - that is, after the feasibility of eradication had been amply demonstrated and when only a million or so dollars stood between success and failure. As Fenner et al. (1988: 1364) put it, "The benefits to all countries of eradicating smallpox would appear so great and so clear that it is difficult to understand why there were problems in obtaining the requisite resources and political commitment."

Certainly, efforts were made to communicate the magnitude of the returns that could be earned on the investment in eradication. In recommending that the WHA support an intensified program, for example, the Executive Board emphasized "that all (emphasis added) countries will make long-term savings after the global eradication of the disease has been achieved," and yet the vote in favor of the program barely passed. D. A. Henderson also "endeavored to persuade USAID and other parts of the government of what an extraordinarily good investment the program was for the US strictly in terms of the savings the country would

seaman, returning home from the Pacific, unwittingly imported the disease, and infected 24 others, of whom four died (Hopkins \& Millar, 1996). About 2,500 persons exposed to the disease had to be quarantined (Sencer $\&$ Axnick, 1973). And of the 300,000 residents of Stockholm who were vaccinated in the wake of the epidemic (Hopkins \& Millar, 1996), about 200 had reactions requiring hospitalization (Sencer \& Axnick, 1973). For Sweden, the memory of this outbreak may have made the benefits of eradication especially palpable.

${ }^{51}$ This is the approach recommended by Shimizu and Sandler (2002), who apply the technique to the public good of peacekeeping.

${ }^{52}$ Analysis conducted using the program STATA. There were $N=121$ observations (the data are shown in Table 4). Kendall's score, representing the number of concordant pairs minus the number of discordant pairs, was equal to 2,524, with a standard error (corrected for ties, as required for tau-b) of 350.7. Using a normal approximation with a continuity correction, STATA calculates the $z$ value and carries out the (two-sided) hypothesis test. This shows that the hypothesis that contributions and assessments are independent is strongly rejected, with Prob $>|z|=0.0000$. 
realize," but discovered that "nobody was the least bit interested!"53 The irony is that, while officials seem not to have supported eradication for this reason, they do celebrate its success on the basis that it earned a high return for the contributing countries. For example, Benjamin Gilman, Chairman of the United States House of Representatives Committee on International Relations, stated in a May 20, 1998 hearing that smallpox eradication saved the world \$168 billion, and the US $\$ 17$ billion, in healthcare costs. "Over 30,000,000 people are alive today because smallpox is gone," Gilman said. "Our investment in smallpox eradication repays our taxpayers every 26 days."

This contrast is not entirely surprising. Before eradication was achieved, the greed factor in the financing game would have made countries want to hold back their contributions, in the belief and hope that others would fill the gap. After eradication was certified, however, countries would want to justify their contributions, and celebrate their achievement. The challenge for fund raising would thus seem to be more than just demonstrating the huge global and even national returns to eradication. There is also a need to coordinate contributions. It is noteworthy that the smallpox eradication campaign did not employ a professional staff "whose full-time responsibility it was to solicit voluntary contributions even though two-thirds of all international funds for the programme were expected to be provided from this source." Instead, as Fenner et al. (1988: 1356) go on to note, "the staff of the smallpox eradication programme undertook to raise these funds as best they could. ..." Lacking "the expertise, the necessary political contacts and the time," however, "their success was limited." 54 Though theory shows that full financing is incentive compatible, experimental evidence warns that full financing is not automatic.

Domestic politics may also have affected contributions. Though the costs of contributing to the eradication effort would be diffused (being financed by taxpayers), the benefits would be diffused, too; no single interest group would benefit hugely from the effort. Indeed, the benefit of eradication to the industrialized countries would be realized only by future generations (having been vaccinated previously, the current generation was already protected from infection). Moreover, no commercial interest would either lose or gain from eradication. ${ }^{55}$ If Putnam (1988: 451) were right - if "What counts [for domestic politics] is not total national costs and benefits, but their incidence, relative to existing coalitions and proto-coalitions" then financing of eradication might have proved shaky not because no coalition spoke against eradication but because no politically powerful coalition spoke strongly in favor of it. ${ }^{56}$

\section{Lessons for polio eradication}

The polio eradication initiative seems to have learned from the smallpox experience. Contributions from philanthropic organizations have shrunk the international financing gap. A single foundation, Rotary International, has contributed over $\$ 500$ million, and lobbied for state funding. Two other foundations (Gates and the United Nations) have contributed more

\footnotetext{
${ }^{53}$ Personal communication, 24 September 2003.

${ }^{54}$ I am grateful to Bruce Aylward for drawing my attention to this passage in the Fenner et al. (1988) book.

${ }^{55}$ As noted in the introduction, the vaccine market was competitive, and so there were no rents to be gained or lost by eradication. See Geoffard and Philipson (1997) for an economic analysis of eradication from the public and private perspectives (but without considering the international aspects of eradication).

${ }^{56}$ DeSombre (2000) has similarly argued that (at least in the area of environmental policy) a congruence of interests is required to internationalize a domestic policy: not only a favorable cost-benefit ratio, but also a competitive advantage for industry. Here, no such advantage existed.
} 
than $\$ 25$ million each (WHO, 2003 a). ${ }^{57}$ And the financing effort has been professionalized. Aylward et al. (2003b: 913) have argued for the need to target "political decision-makers, by means such as professional lobbying firms and international forums to establish the commitment of heads of state." And Rotary International has calculated financing targets - fair shares of the financial burden - based on the focal point suggested here: the WHO's regular assessments. However, this approach to fund-raising has had only mixed success:

“... of the 22 WHO Member States who are members of the OECD's Development Assistance Committee that makes up the community of 'traditional' ODA donors, only 16 have contributed to the eradication initiative. Of these, only 7 contributed the equivalent or more than their estimated 'share,' 6 are 'free-riders' in that they made no financial contribution to eradication, while the remaining 9 contributed substantially less than their estimated 'share' of the total budget of US \$2,750 million dollars between 1985 and 2005" (Aylward et al., 2003a: 48).

A possible reason for this uneven record may be that the polio eradication initiative started out on the wrong foot. Though the World Health Assembly voted to eradicate polio in 1988, the commitment needed to see the initiative through to a successful conclusion was not developed. Just as with the first declaration on smallpox eradication, countries voting in favor of the resolution were not required to finance the effort needed to achieve the ambition. Even worse, "No data were presented on the estimated human and financial resources that would be required, nor was there a clear statement on the strategies that would need to be pursued and in what timeframe" (Aylward et al., 2003a: 46). A strategy was especially needed for deciding what to do after wild polio transmission had ceased globally, because the vaccine that works best at eliminating the disease (the oral polio vaccine) also creates the risk of the disease being re-introduced by circulating vaccine-derived polioviruses. This strategy was finally agreed in 2003 (WHO, 2003b), five years after the program began, and after billions of dollars had already been spent. The strategy is not fail safe ${ }^{58}$ Indeed, partly for this reason, industrialized countries have already decided to continue to vaccinate using the inactivated polio vaccine indefinitely (Sangrujee, Cáceres, \& Cochi, 2004; see also Section 14). These countries will thus receive no benefits from eradication, helping to undercut the economic rationale for eradicating the disease.

As for the approach used for financing, Aylward et al. (2003a: 48) note that the "fair share' concept has been most useful in negotiations with those donors who were institutionally committed to the concept of polio eradication. ... Such donors readily engaged in discussion as to the 'appropriate' level of contribution. The fair share concept had limited utility, however, when seeking donor government resources from those who were opposed, for whatever reason, to the concept from the outset." ${ }^{\text {59 }}$ This experience only reinforces the basic lesson of

\footnotetext{
57 Though these contributions are welcome, they also point to under-funding by countries. As noted by Olson (1965: 13), countries do not rely on philanthropy to supply essential national public goods.

${ }^{58}$ The strategy involves stopping OPV use in all countries simultaneously, with future outbreaks being contained locally by further application of OPV. For an analysis of the problems with this approach, see Miller, Barrett, and Henderson (2006). Sutter, Cáceres and Mas Lago (2004) evaluate the different post-certification strategies.

${ }^{59}$ This opposition stems partly from a disagreement about the value of a "targeted" health objective such as polio eradication, as opposed to a policy of strengthening primary health care in poor countries. Targeted programs have advantages. They are preferred by international donors; and, as a development policy, eradication is financially sustainable in a way that no other development assistance can be. Critics, however, question whether they displace other sources of overseas development assistance, whether they offer developing countries the help they need most, and whether they may even weaken health systems overall (see Taylor, Cutts, and Taylor, 
the smallpox eradication program - that free riding is a real problem, but one that is more complicated than suggested by theory.

\section{The terrorist threat}

With vaccination having been discontinued for a quarter of a century, the world's overall immunity to smallpox is probably little different today than it was when Jenner made his famous discovery. By one estimate, herd immunity may now be around 18 percent (Gani \& Leach, 2001); over time, it will only fall (unless mass vaccination is restarted). To prevent an epidemic, herd immunity would need to be at least 80 percent. Making matters worse, a significant fraction of today's population is immune-compromised. These individuals (including persons with HIV1AIDS and persons taking powerful new cancer drugs) cannot be given the live smallpox vaccine. ${ }^{60}$ So, while eradication, accompanied by cessation of vaccination, has yielded the world a huge dividend, it has also made the world exceptionally vulnerable to a new release of the smallpox virus. With hindsight, was eradication really a good deal?

Concern about a possible bioterrorist attack using smallpox is not new. Fenner et al. (1988: 1341) considered the possibility, concluding that, "the risk of any such act leading to the re-establishment of endemic smallpox should not be exaggerated." The reason is that "smallpox spreads comparatively slowly, by face-to-face contact. Unless the public health services had completely broken down, the existence of reserve stocks of vaccine... would ensure the containment of any outbreak that followed a deliberate release of variola virus." After smallpox was eradicated, vaccine was stockpiled in the United States and a number of other countries; the WHO also kept a reserve. This was thought sufficient to address the risk of a new outbreak. Indeed, confidence was so high that the International Health Regulations were amended in 1982 to take smallpox off the list of notifiable diseases. Negotiations were also underway to destroy the remaining quantities of variola (see below). Doing so, it was believed, would have made smallpox extinct and shut the door on this scourge forever.

The terrorist attacks of September 11th, 2001 and the anthrax attacks of October 2001 changed this calculation of risk. In response, a number of steps have been taken to reduce the probability of a terrorist attack, including the toppling of the Taliban regime in Afghanistan, an increase in intelligence gathering, and the freezing of terrorist assets. Steps have also been taken to reduce the consequences of an attack. In the specific case of smallpox, the United States and other industrialized countries began stockpiling more vaccine - the US has stockpiled enough for every American - and the industrialized countries also cooperated in establishing a Smallpox Vaccine Bank, from which the WHO may draw to control outbreaks arising in developing countries. Further international measures are also being taken - for example, to ensure that at least two manufacturers can produce large quantities of vaccine, should the need arise. The recently revised International Health Regulations once again require countries to notify the WHO in the event of a smallpox outbreak. Stocks of variola

1997). Responding to these criticisms, and drawing from field studies on the polio eradication initiative, proponents argue that health systems may not be harmed by targeted programs, and may even be helped by them (Loevinsohn et al., 2002).

${ }^{60}$ Such persons, if at serious risk of becoming infected, can be given vaccinia immune globulin (if the supplies are available) along with the vaccine. 
virus, far from being destroyed, are now being used to develop new diagnostic tests, vaccines, and drug treatments. ${ }^{61}$

Vaccination has also been restarted, though on a limited scale. The United States has vaccinated half a million military personnel. It also planned to vaccinate about the same number of hospital, health care, and emergency services workers. The plan failed; fewer than 40,000 "front-line responders" have been vaccinated. One reason for this failure was noted in Section 2: the conflict between the individual and the public interest. Another reason is that the change in policy was not accompanied by any information about an elevated risk of a smallpox release. That risk is difficult to calculate. Smallpox is different from other biological agents. Unlike anthrax, it does not exist in nature. Unlike polio, it cannot be engineered from scratch. Given current technology, smallpox must be acquired from existing stocks. After eradication was certified, the WHO recommended that all laboratories destroy their stocks of variola virus - and all reported doing so. This restricted the remaining stocks to the two WHO reference laboratories, based in Moscow and Atlanta. These stocks still exist; and as mentioned before they are being used today for research purposes. There is a chance, however, that covert stocks may also exist. It is this risk that the stockpiles and related policies are guarding against today.

The decision to eradicate a disease must plainly take account of the terrorist risk, as well as of the costs of the measures undertaken to limit it. The economics of smallpox eradication are so overwhelming, however, that these considerations are unlikely to have changed the collective decision to eradicate. Indeed, though eradication is potentially reversible, so is the decision to terminate mass vaccination. That countries have chosen not to revert to a policy of mass vaccination testifies to the enduring benefit of smallpox eradication.

Polio is different. Polio samples exist in laboratories all over the world, polioviruses are more difficult to detect, and as mentioned before polio can be synthesized. In addition, there exists a safe polio vaccine - the inactivated polio vaccine, used now in industrialized countries. As noted by the WHO (2003: 67), “. . .the risks of international terrorism have substantially affected the willingness of some policy-makers to plan for the discontinuation of routine polio immunization in the near future, regardless of the economic benefits." Concern about a possible bioterrorist attack has thus changed the economics of eradicating this disease. It is likely also to have changed the economics of eradicating other diseases, such as measles. Among the global diseases at least, smallpox remains the exception. ${ }^{62}$

\section{Conclusion}

The eradication of smallpox stands as perhaps the greatest achievement of international cooperation ever. Theory helps explain why the effort succeeded. The weakest link nature of eradication, coupled with a fantastically attractive benefit-cost ratio, meant that the smallpox eradication game required developed country financing of elimination in developing countries, and the discrete nature of the effort meant that this could be achieved by coordination.

\footnotetext{
${ }^{61}$ It is sometimes noted that steps such as these serve to deter a terrorist attack. This is unclear, but to the extent that a smallpox attack is deterred, the effect may only be to cause terrorists to shift to another mode of attack; see Sandler (2005).

${ }^{62}$ It is unlikely, though not impossible, that terrorists would want to release the nematode that causes guinea worm disease, which afflicts the poorest people living in the poorest, tropical countries, should that eradication effort succeed.
} 
The success of the campaign did not hinge on the WHO being able to enforce an agreement to eradicate.

It is harder for theory to explain why the effort nearly failed. Two reasons stand out. The first is free riding. While the developed countries had a strong incentive to finance the eradication initiative, each country would prefer that others contributed instead - a result borne out in experimental studies. The second is domestic politics. While theory takes states to be monoliths, domestic politics would not have provided strong incentives for countries to finance the eradication effort, even though financing was in the interests of every developed country.

Acknowledgements I am grateful to D. A. Henderson, former head of the Smallpox Eradication Unit at the World Health Organization (WHO), and Bruce Aylward, Coordinator of the WHO's Global Polio Eradication Initiative, for commenting on an earlier draft and for sharing their respective experiences; to Bram Cadsby for comments on an earlier draft; to Andrew Moravcsik for discussing the politics of financing global public goods; to Todd Sandler for advice on the correlation analysis; and to Shlomi Dinar and Cristin Tighe for research assistance. Seminar participants at Columbia University and Stanford University, an anonymous referee, and an associate editor also provided helpful comments on an earlier draft.

\section{References}

Admati, A.R., \& Perry, M. (1991). Joint projects without commitment. Review of Economic Studies, 58, 259-276.

Anderson, R.M., \& May, R.M. (1991). Infectious diseases of humans: dynamics and control. Oxford: Oxford University Press.

Andreoni, J. (1998). Toward a theory of charitable fund-raising. Journal of Political Economy, 106(6), 11861213.

Aylward, R.B., Acharya, A., England, S., Agocs, M., \& Linkins, J. (2003a). Polio eradication. In: Smith, R.R., Beaglehole, Woodward, D., \& Drager, N. (Eds.), Global public goods for health: health economic and public health perspectives, (pp. 33-53). Oxford: Oxford University Press.

Aylward, R.B., Acharya, A., England, S., Agocs, M., \& Linkins, J. (2003b). Global health goals: lessons from the worldwide effort to eradicate poliomyelitis. The Lancet, 362, 909-914.

Barrett, S. (2001). International cooperation for sale. European Economic Review, 45, 1835-1850.

Barrett, S. (2003a). Environment and statecraft: the strategy of environmental treaty-making. Oxford: Oxford University Press.

Barrett, S. (2003b). Global disease eradication. Journal of the European Economic Association, 1, 591-600.

Barrett, S. (2004). Eradication vs. control: the economics of global infectious disease policy. Bulletin of the World Health Organization, 82, 683-688.

Barrett, S., \& Hoel, M. (2003). Optimal disease eradication. Unpublished manuscript.

Basu, R.N., Jezek, Z., \& Ward, N.A. (1979). The eradication of smallpox from India. New Delhi: World Health Organization.

Brilliant, L.B. (1985). The management of smallpox eradication in India. Ann Arbor: University of Michigan Press.

Cadsby, C. B., \& Maynes, E. (1998). Corporate takeovers in the laboratory when shareholders own more than one share. Journal of Business, 71(4), 537-572.

Cadsby, C.B., \& Maynes, E. (1999). Voluntary provision of threshold public goods with continuous contributions: experimental evidence. Journal of Public Economics, 71, 53-73.

Cadsby, C.B., Hamaguchi, Y., Kawagoe, T., Maynes, E., \& Song, F. (2003). Cross-national gender differences in behavior in a threshold public goods game: Japan versus Canada. Unpublished manuscript. Department of Economics, University of Guelph.

Compte, O., \& Jehiel, P. (2003). Voluntary contributions to a joint project with asymmetric agents. Journal of Economic Theory, 112(2), 334-342.

Cooper, R.N. (1989). International cooperation in public health as a prologue to macroeconomic cooperation. In: Cooper, R.N. Eichengreen, B., Henning, C.R., Holtham, G., \& Putnam, R.D. Can nations agree? Washington, DC: Brookings Institution.

Crosby, A.W. (1986). Ecological imperialism: the biological expansion of Europe, 900-1900. Cambridge: Cambridge University Press. 
DeSombre, E.R. (2000). Domestic sources of international environmental policy. Cambridge, MA: MIT Press.

Fehr, E., \& Gächter, S. (2000). Cooperation and punishment in public goods experiments. American Economic Review, 90(4), 980-994.

Fenner, F. (1993). Human monkeypox, a newly discovered human virus disease. In: Morse, S.S. (Ed.), Emerging viruses, pp. 176-183 New York: Oxford University Press.

Fenner, F., Henderson, D.A., Arita, I., Jezek, Z., \& Ladnyi, I.D. (1988). Smallpox and its eradication. Geneva: World Health Organization.

Gani, R., \& Leach, S. (2001). Transmission potential of smallpox in contemporary populations. Nature 414, $748-751$.

Geoffard, P.-Y., \& Philipson, T. (1997). Disease eradication: private versus public vaccination. American Economic Review, 87(1), 222-230.

Glynn, I., \& Glynn, J. (2004). The life and death of smallpox. Cambridge: Cambridge University Press.

Henderson, D.A. (1999). Eradication: lessons from the past. Morbidity and Mortality Weekly Report, 48, $16-22$.

Hinman, A. (1999). Eradication of vaccine-preventable diseases. Annual Review of Public Health, 20, 211229.

Hirshleifer, J. (1983). From weakest-link to best-shot: the voluntary provision of public goods. Public Choice, 41, 371-386.

Hopkins, D.R. (1983). Princes and peasants: smallpox in history. Chicago: University of Chicago.

Hopkins, D.R. \& Millar, J.D. (1996). Editorial note. Morbidity and Mortality Weekly Report, 45, 538-45.

Hopkins, D.R., Ruiz-Tiben, E., Diallo, N., Withers, Jr., P.C., \& Maguire, J.H. (2002). Dracunculiasis eradication: and now, Sudan. American Journal of Tropical Medicine and Hygiene, 67(4), 415-22.

Isaac, R.M., Schmidtz, D., \& Walker, J.M. (1989). The assurance problem in a laboratory market. Public Choice, 62, 217-236.

List, J.A., \& Lucking-Reiley, D. (2002). The effects of seed money and refunds on charitable giving: experimental evidence from a university capital campaign. Journal of Political Economy, 110(1), 215-233.

Loevinsohn, B., Aylward, B., Steinglass, R., Ogden, E., Goodman, T., \& Melgaard, B. (2002). Impact of targeted programs on health systems: a case study of the polio eradication initiative. American Journal of Public Health, 92(1), 19-23.

McNeill, W.H. (1977). Plagues and peoples. New York: Doubleday.

Miller, M., Barrett, S., \& Henderson, D.A. (2006). Control and eradication. In: Jamison, D.T., Alleyne, G., Breman, J., Claeson, M., Evans, D.B., Jha, P., Measham, A.R., Mills, A., \& Musgrove, P.R. (Eds.), Disease control priorities in developing countries. 2nd edition. Oxford: Oxford University Press, 1163-1176.

Olmstead, A.L., \& Rhode, P.W. (2004). An impossible undertaking: the eradication of bovine tuberculosis in the United States. Journal of Economic History, 64(3), 1-39.

Olson, M. (1965). The logic of collective action. Cambridge, MA: Harvard University Press.

Olson, M., \& Zeckhauser, R. (1966). An economic theory of alliances. Review of Economics and Statistics, 48, 266-279.

Putnam, R. (1988). Diplomacy and domestic politics: the logic of two-level games. International Organization, 42, 427-460.

Ramaiah, T.J. (1976). Cost-benefit analysis of the intensified campaign against smallpox in India. National Institute of Health Administration and Education Bulletin, 9(3), 169-203.

Sandler, T. (1992). Collective action: theory and applications. Ann Arbor: University of Michigan Press.

Sandler, T. (2005). Collective versus unilateral responses to terrorism. Public Choice, 124, 75-93.

Sangrujee, N., Caceres, V.M., \& Cochi, S.L. (2004). Cost analysis of post-polio certification immunization policies. Bulletin of the World Health Organization, 82(1), 9-15.

Schelling, T.C. (1960). The strategy of conflict. Cambridge, MA: Harvard University Press.

Sencer, D.J., \& Axnick, N.W. (1973). Cost benefit analysis. International symposium on vaccination against communicable diseases, Monaco 1973; Symposia series in immunobiological standardization, 22, 37-46.

Shimizu, H., \& Sandler, T. (2002). Peacekeeping and burden-sharing, 1994-2000. Journal of Peace Research, 39(6), 651-668.

Suleiman, R., \& Rapoport, A. (1992). Provision of step-level public goods with continuous contribution. Journal of Behavioral Decision Making, 5, 133-153.

Sutter, R.W., Cáceres, V.M., \& Lago, P.M. (2004). The role of routine polio immunization in the postcertification era. Bulletin of the World Health Organization, 82(1), 31-39.

Taylor, C.E., Cutts, F., \& Taylor, M.E. (1997). Ethical dilemmas in current planning for polio eradication. American Journal of Public Health, 87(6), 922-916.

Vesterlund, L. (2003). The informational value of sequential fundraising. Journal of Public Economics, 87 (3-4), 627-657. 
World Health Assembly (1966). Eighth meeting of the nineteenth World Health Assembly, 12 May 1966, Official Records of the World Health Organization, 152, 288.

World Health Organization (2001). Global polio eradication initiative: estimated external financial resource requirements for 2002-2005 as of 1 September 2001. Geneva: WHO.

World Health Organization (2003a). Global polio eradication initiative: estimated external financial resource requirements for 2004-2008 as of December 2003. Geneva: WHO.

World Health Organization (2003b). Global polio eradication initiative strategic plan 2004-2008. Geneva: WHO.

World Health Organization (2003c). World Health Report 2003: Shaping the future. Geneva: WHO.

World Health Organization (2005). Global polio eradication initiative: 2004 annual report. Geneva: WHO.

Yekutiel, P. (1980). Eradication of infectious diseases: a critical study. Basel: S. Karger. 